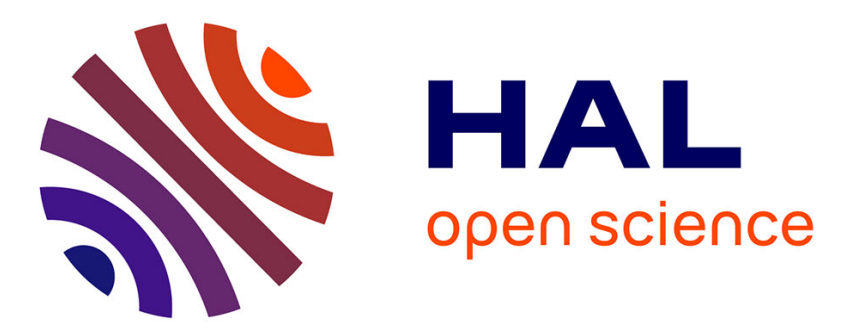

\title{
The lack of rhodanese RhdA affects the sensitivity of Azotobacter vinelandii to oxidative events
}

Angelo Cereda, Aristodemo Carpen, Gianluca Picariello, Gabriella Tedeschi, Silvia Pagani

\section{- To cite this version:}

Angelo Cereda, Aristodemo Carpen, Gianluca Picariello, Gabriella Tedeschi, Silvia Pagani. The lack of rhodanese RhdA affects the sensitivity of Azotobacter vinelandii to oxidative events. Biochemical Journal, 2009, 418 (1), pp.135-143. 10.1042/BJ20081218 · hal-00479048

\section{HAL Id: hal-00479048 https://hal.science/hal-00479048}

Submitted on 30 Apr 2010

HAL is a multi-disciplinary open access archive for the deposit and dissemination of scientific research documents, whether they are published or not. The documents may come from teaching and research institutions in France or abroad, or from public or private research centers.
L'archive ouverte pluridisciplinaire HAL, est destinée au dépôt et à la diffusion de documents scientifiques de niveau recherche, publiés ou non, émanant des établissements d'enseignement et de recherche français ou étrangers, des laboratoires publics ou privés. 


\title{
The lack of rhodanese RhdA affects the sensitivity of Azotobacter vinelandii to oxidative events.
}

\author{
Angelo Cereda, Aristodemo Carpen, Gianluca Picariello§, Gabriella Tedeschi^ ${ }^{\wedge}$ and Silvia \\ Pagani**
}

Dipartimento di Scienze Molecolari Agroalimentari and ,^ D.I.P.A.V.-sezione di Biochimica., Università di Milano,Milano. ${ }^{\S}$ Istituto di Scienze dell'Alimentazione, CNR, Avellino. Italy.

**To whom correspondence should be addressed (e mail: silvia.pagani@unimi.it)

Running title: Effects of the lack of RhdA in Azotobacter vinelandii

Key words: rhodanese-domain proteins; Azotobacter vinelandii; RhdA; oxidative stress.

The rhdA gene of Azotobacter vinelandii codes for a rhodanese-domain protein (RhdA) with an active-site loop structure which has not currently been found in proteins of the rhodanese-homology superfamily. Considering the lack of information on the functional role of the ubiquitous rhodaneses, we undertook a study of in vivo functions of RhdA by using an A.vinelandii mutant strain (MV474) in which the rhdA gene was disrupted by deletion. Preliminary phenotypic characterization of the rhdA mutant suggested that RhdA could exert protection of Fe-S enzymes which are easy targets for oxidative damage. To highlight the role of RhdA in preserving sensitive Fe-S clusters, in the current study we analyzed the defects of the RhdA null strain by exploiting growth conditions able to enhance the catalytic deficiency of enzymes with vulnerable Fe-S clusters. We found that RhdA lack impaired A.vinelandii growth in the presence of gluconate, a carbon source that activates the Entner-Doudoroff pathway in which the first enzyme 6phosphogluconate dehydratase employs a $4 \mathrm{Fe}-4 \mathrm{~S}$ cluster as active-site catalyst. By combining proteomics, enzymatic profiles, and model systems to generate oxidative stress, evidence is provided that to rescue the effects of RhdA lack A.vinelandii needed to activate defensive activities against oxidative damage. The possible functionality of RhdA as a redox switch which helps A.vinelandii in maintaining cellular redox balance was investigated by using an in vitro model system that proved reversible chemical modifications in the highly reactive RhdA Cys 230 thiol.

\section{INTRODUCTION}

The ubiquitous rhodanese-domain proteins in vitro catalyse the transfer of a sulfur atom from a suitable sulfur donor (thiosulfate for rhodaneses, and 3-mercaptopyruvate for 3-mercaptopyruvate sulfurtransferases) to cyanide, with concurrent formation of thiocyanate [1]. In the majority of organisms the proteins of this homology superfamily (Accession number: PF00581; http://www.sanger.ac.uk/Software/Pfam/) are present as paralogs, and they are found as tandem rhodanese repeats, single domain proteins or in combination with distinct protein domains [2]. The wide variability in the amino acids of the active-site loop of rhodanese-domain proteins [2] makes it conceivable that substrate recognition and biological interactions are driven by the specific activesite structure. Starting from the finding that bovine rhodanese [3], Escherichia coli GlpE [4], and the 3-mercaptopyruvate sulfurtransferase from Leishmania [5] have higher affinity for reduced thioredoxins than for cyanide, the concept that the abundant rhodanese-like proteins could have roles in managing processes of stress tolerance is emerging, although in vivo experimental evidence is still lacking. The relevance of specific rhodanese-like proteins in the maintenance of redox homeostasis has been suggested by in vitro studies with rat mercaptopyruvate sulfurtransferase [67]. As for bacterial rhodanese-domain proteins, possible involvement in physiological processes related to xenobiotic-induced oxidative-stress and detoxification was indicated by proteomic analyses [8-9]. Recently, we have found evidence that rhodanese-like enzymes favoured Polycyclic Aromatic Hydrocarbons (PAHs) degradation in selected Mycobacterium strains [10]. This 
experimental evidence suggests that rhodanese domains might function as regulatory devices in specific physiological situations, but the redundancy of these proteins in the same organism make it difficult to unravel their cellular roles.

Among the redundant rhodanese-homology proteins of A.vinelandii, the tandem domain protein RhdA [11] contains an active-site motif (HCQTHHR) not commonly found in rhodanese-domain proteins. Crystallographic investigations [12] showed that the RhdA catalytic center is surrounded by a strong positive electrostatic field that originates from the peculiar active-site loop structure, and from the vicinity of positively charged groups. Considering the lack of general information on the biological role of rhodaneses, we undertook a study of in vivo functions of RhdA by using an A.vinelandii mutant strain (MV474) in which the rhdA gene was disrupted by deletion [11]. Initial characterization of MV474 grown in a sucrose medium, revealed that the lack of RhdA enhanced the expression of enzymes of the polyhydroxybutyrate biosynthetic operon, giving rise to early accumulation of polyhydroxybutyrate, and negatively affected the activity of tricarboxylic acid cycle Fe-S enzymes [13]. The effect on aconitate hydratase was dramatic, in spite of the comparable expression of aconitate hydratase polypeptides in wild-type and rhdA mutant strains. These results [13] led to the proposal that RhdA triggers protection to oxidative events that in the aerobe A.vinelandii led to the inactivation of enzymes containing labile Fe-S [14]. To highlight the role of RhdA in preserving sensitive Fe-S clusters, in the current study, we analyzed the defects of the RhdA null strain MV474 by exploiting growth conditions that enhance the catalytic deficiency of enzymes with vulnerable Fe-S clusters [15]. We found that RhdA lack impaired A.vinelandii growth in the presence of gluconate, a carbon source that activates the Entner-Doudoroff (ED) pathway [16] in which the first enzyme 6-phosphogluconate dehydratase employs a vulnerable $4 \mathrm{Fe}-4 \mathrm{~S}$ cluster as active-site catalyst [17]. The use of gluconate as carbon source proved to be an useful growth condition in which to make an in-depth study of the initially hypothesized [13] role of RhdA in protecting cells from oxidative damage. By combining proteomics, enzymatic profiles, and model systems to generate oxidative stress, in this report we present evidence to show that to rescue the effects of the lack of RhdA A.vinelandii needed to activate defensive activities against oxidative damage. The possible functionality of RhdA as a redox switch which helps A.vinelandii in maintaining redox balance was investigated by using an in vitro model system to prove chemical modifications in the high-reactive RhdA Cys230 thiol, the only one present in the molecule.

\section{EXPERIMENTAL}

\section{Bacterial Strains and Growth Conditions}

The A.vinelandii strains used in this study were UW136 and a derivative of UW136 (MV474) in which disruption of the $r h d A$ gene was achieved by the insertion of a KIXX cassette, following deletion of $584 \mathrm{bp}$ as described in Ref. 11. Western blot analysis with MV474 [13] clearly showed that no protein corresponding to RhdA is expressed in this mutant. Cells were grown aerobically in Burk's medium for $24 \mathrm{~h}$ at $30^{\circ} \mathrm{C}$, supplemented with $0.2 \%$ gluconate and $15 \mathrm{mM}$ ammonium acetate (BGN medium). When the optical density reached $\mathrm{OD}_{600}=2.0$, the cells were spun down at $3800 \mathrm{x}$ g for $10 \mathrm{~min}$, and stored at $-80^{\circ} \mathrm{C}$. For oxidative stress sensitivity assays, cells were grown in the above conditions up to $\mathrm{OD}_{600}=0.800$, then the cultures of either UW136 or MV474 strains were divided into two equal samples one of which was treated with phenazine methosulfate (PMS, final concentration $15 \mu \mathrm{M})$.

\section{Sample preparation and Gel Electrophoresis}

Cells were harvested by centrifugation (30 min at $2000 \mathrm{xg}$ ), and suspended in a $10 \mathrm{mM}$ Tris- $\mathrm{HCl}$ pH 8.0 buffer containing $1.5 \mathrm{mM} \mathrm{MgCl} 2,10 \mathrm{mM} \mathrm{KCl}, 0.1 \%$ SDS. A buffer volume approximately equal to the packed cell volume was used. Before analysis, $100 \mu \mathrm{L}$ of sample were solubilized in 1 $\mathrm{mL}$ of lysis buffer (7 M urea, $2 \mathrm{M}$ thiourea, 4\% w/v CHAPS, $65 \mathrm{mM}$ dithiothreitol (DTT), 2\% IPG buffer $\mathrm{pH}$ 4-7 (Amersham Biosciences), and incubated for $20 \mathrm{~min}$ in ice. Protein concentrations were estimated using a 2-DE quant Kit (Amersham Biosciences) before adding bromophenol blue. 
Proteins were separated by two-dimensional electrophoresis (2-DE) using Immobiline Dry-Strips ( $\mathrm{pH} 4-7$ linear, $14 \mathrm{~cm}$ long; Amersham Biosciences). The sample (180 $\mu \mathrm{g}$ of proteins) was loaded on the immobilized $\mathrm{pH}$ gradient strip after overnight in-gel reswelling procedure (Amersham Biosciences Instruction Manual). The isoelectric focusing (IEF) was carried out at $20^{\circ} \mathrm{C}$ using a Multiphor II electrophoresis unit (Amersham Biosciences) with the following program: $75 \mathrm{~V}$ for $1 \mathrm{~h}$, $300 \mathrm{~V}$ for $1 \mathrm{~h}, 300-1000 \mathrm{~V}$ in $4 \mathrm{~h}, 1000-8000 \mathrm{~V}$ in $6 \mathrm{~h}, 8000 \mathrm{~V}$ for $2 \mathrm{~h}$, and $50 \mathrm{~V}$ for $1 \mathrm{~h}$. After focusing, Immobiline Dry-Strips were equilibrated for $15 \mathrm{~min}$ at room temperature in the equilibration buffer (50 mM Tris- $\mathrm{mCl}, \mathrm{pH} 8.8,6 \mathrm{M}$ urea, 30\% v/v glycerol, $2 \% \mathrm{w} / \mathrm{v}$ SDS) containing $1 \% \mathrm{w} / \mathrm{v}$ DTT, followed by a second incubation step $(15 \mathrm{~min})$ in the equilibration buffer in the presence of $2.5 \% \mathrm{w} / \mathrm{v}$ iodoacetamide. Separation in the second dimension (SDS-PAGE) was carried out on homogeneous $12 \% \mathrm{~T}$ gels, and electrophoresis was conducted at $10 \mathrm{~mA}$ per gel for $30 \mathrm{~min}$, and at $25 \mathrm{~mA}$ for $4 \mathrm{~h}$ in a Hoefer SE600 Electrophoresis Unit. Gels were silver stained as described in [18]. In order to corroborate the reproducibility of the results, at least three independent experiments for each strain were performed, and three gels were run for each sample. Silver-stained gels were digitized using an EPSON Expression 1680 Pro scanner (Epson, Milan, Italy). ImageMaster 2D Platinum software (Amersham Biosciences) was used for the gel image analysis, including quantification of the spot intensities that is performed on a volume basis (i.e. values were calculated from the integration of spot optical intensity over the spot area, and referred as $\% \mathrm{~V}$ ). The $\% \mathrm{~V}$ is the ratio between the volume of a spot and the sum of the volume of all the spots detected in the same gel. Gel patterns from independent analyses were matched together, and the relative volume of each spot $(\% \mathrm{~V})$ in the two gel sets (UW 136 and MV474 A.vinelandii strains) were compared. Significant changes of the abundance of selected proteins (Table 1) was estimated with Student's $t$ test $(p<0.05)$. The average expression ratio between MV474 and UW136 strains was calculated from the averages of relative volumes of five replicates.

\section{Mass Spectrometry Analysis and identification of protein spots}

In-gel enzymatic digestion of the spots and peptide extraction were carried out as described in ref 19. MALDI-TOF MS analysis was performed in a Voyager DE-Pro spectrometer (PerSeptive BioSystems,Framingham, MA). External mass calibration was performed with low-mass peptide standards and mass measurement accuracy was $\pm 0.3 \mathrm{Da}$. The mass spectra were acquired in reflector mode using Delay Extraction (DE) technology. Raw data were elaborated using Data Explorer 5.0 software furnished by the manufacturer. The software package, Protein Prospector MS-Fit, available on-line at the web site of the University of San Francisco (CA, USA) (http://prospector.ucsf.edu), was used to identify protein spots from NCBI protein and gene sequence databases. A number of top candidates with high scores from the peptide matching analysis were further evaluated by comparing their calculated pI and MW using the experimental values obtained from 2-DE gel. These two parameters were used with large tolerances (DpI $=1$ and $\mathrm{DMW}= \pm 15 \% \mathrm{Mw})$ as filters to exclude false positive candidates from the output lists.

\section{Enzymatic Activity Assays}

Enzymatic activities were determined in samples (150-300 $\mu \mathrm{g}$ of proteins) of cell-free extracts anaerobically prepared by sonication (five $30 \mathrm{~s}$ pulses with intermitted 1 min cooling periods) in lysis buffer A (50mM Tris-HCl pH 8, 100mM NaCl, DTT $1 \mathrm{mM})$.

Aconitate hydratase and 6-phosphogluconate dehydratase activities were tested as described in ref. 20 and 21, respectively. Catalase activity was measured through the method described in ref. 22, one unit $(\mathrm{U})$ of enzyme is defined as the amount of enzyme that decomposes $1 \mu$ mole of $\mathrm{H}_{2} \mathrm{O}_{2}$ per $\min$ at $37^{\circ} \mathrm{C}$.

For reactivation experiments, before the activity tests, cell-free extracts were anaerobically incubated $(10 \mathrm{~min})$ at room temperature in the presence of $\mathrm{FeSO}_{4}(1.0 \mathrm{mM})$ and DTT $(5.0 \mathrm{mM})$. Rhodanese activity was tested by the discontinuous method that quantitates the product thiocyanate [23] in the presence of thiosulfate as sulfur donor (TST activity). The assays lasted 1 or 2 min, and 
one unit (U) of enzyme is defined as the amount of enzyme that produces $1 \mu$ mol thiocyanate/min at $37^{\circ} \mathrm{C}$.

For reactivation experiments of PMS-treated purified RhdA (molar ratio RhdA/PMS $=1 / 1$ ), the mixtures after gel filtration $\left(10 \mu \mathrm{M}\right.$ RhdA) were incubated at $4^{\circ} \mathrm{C}$ in the presence of $10 \mu \mathrm{M}$ E.coli reduced thioredoxin (Trx, Sigma), $0.2 \mu \mathrm{M}$ rat liver thioredoxin reductase (Sigma) and $50 \mu \mathrm{M}$ $\mathrm{NADPH}$ in $20 \mathrm{mM}$ phosphate buffer $\mathrm{pH} 7.4$ (final volume $100 \mu \mathrm{L}$ ). In the case of PMS-treated A.vinelandii UW136, the extracts $(200 \mu \mathrm{g}$ protein) were incubated in the presence of $50 \mu \mathrm{M}$ thioredoxin, $0.2 \mu \mathrm{M}$ rat liver thioredoxin reductase, and $100 \mu \mathrm{M}$ NADPH. After $60 \mathrm{~min}$ incubation TST activity was measured.

\section{In vitro study on overexpressed RhdA}

Overespressed His-tagged RhdA, purified as previous described [24], was used to test in vitro effects of the oxidative agent PMS. RhdA $(100 \mu \mathrm{M})$ in $50 \mathrm{mM}$ Tris-HCl pH8, $100 \mathrm{mM} \mathrm{NaCl}$ was incubated aerobically with PMS (final concentration $1 \mathrm{mM}$ ). At fixed incubation times, sample aliquots were gel-filtered by using G-25 Sephadex columns to remove PMS. The gel-filtered samples were subjected to the rhodanese activity test [23], non-reducing SDS-PAGE [25] and MALDI-TOF MS analyses. Densitometric analyses of the electrophoretic pattern were performed on Blue Coomassie stained gels by using ImageMaster 1D Elite software (Amersham Biosciences). The MALDI-TOF MS analysis was performed by using a Bruker Daltonics Reflex IV instrument equipped with a nitrogen laser $(337 \mathrm{~nm})$ and operated in positive linear mode with a matrix of $\alpha$-ciano-4hydroxycinnamic acid. External standards were used for calibration (Bruker protein II calibration standard) and the_mass measurement accuracy was $\pm 1 \mathrm{Da}$. Each spectrum was accumulated for at least 200 laser shots.

\section{Analytical Procedures}

Protein concentration was determined by the Bradford assay [26] using Bovine Serum Albumin (BSA) as standard. Polyhydroxybutyrate (PHB) content was determined by a spectrophotometric method [27].

\section{RESULTS}

\section{The lack of RhdA affects A.vinelandii growth on gluconate as carbon source}

In the sucrose medium, which we employed for our initial experiments, the rhdA mutant MV474 grew as well as the wild-type UW136 strain, but metabolic unbalance of MV474 suggested that the absence of RhdA favored oxidative events in A.vinelandii [13]. To better frame protective cellular roles of RhdA, more critical growth conditions were exploited, and we found that the growth of A.vinelandii MV474 was impaired in the presence of gluconate as carbon source. Utilization of gluconate via the Entner-Doudoroff (ED) pathway [16] involves the activity of 6-phosphogluconate dehydratase, an enzyme containing a 4Fe-4S cluster easy target for oxidative damage [17]. In this growth condition (Fig.1), the lack of RhdA caused significant growth inhibition at early stages, and after 24 hours of growth MV474 reached a final culture density of about $90 \%$ of that of the wildtype strain. At this stage, accumulation of polyhydroxybutyrate (PHB) was 8 fold higher in the RhdA null mutant than in UW136. PHB content (determined in three separated growth experiments) was $163 \pm 10 \mu \mathrm{g} \mathrm{mg}$ protein $^{-1}$ in UW136, and $1320 \pm 25 \mu \mathrm{g} \mathrm{mg}$ protein ${ }^{-1}$ in the mutant strain, confirming that the metabolic profile of the mutant MV474 did favor synthesis and accumulation of this polymer. Higher accumulation of PHB in the RhdA null mutant than in UW136 was, indeed, observed also when sucrose was the carbon source [13]. PHB accumulation is generally considered a "cell survival mechanism" [28] that endows bacteria with enhanced "stress" tolerance [29], thus indicating that PHB accumulation in MV474 represents a response to the physiological unbalance inferred by the lack of RhdA. 


\section{Protein expression in A.vinelandii wild-type and RhdA null mutant strains}

Comparative proteomics of gluconate-cultured UW136 and MV474 A.vinelandii strains were performed with the aim of identifying the relative abundance of specific enzymes strictly related to the metabolic picture evidenced in the absence of RhdA. The protein spots listed in Table 1 were identified by peptide mass fingerprinting, and their relative abundance (in term of relative volume of each spot, $\% \mathrm{~V}$ ) was accurately calculated from independent gel patterns (five experimental repeats) for each set (rhdA null mutant and UW 136 A.vinelandii strains). Through this comparative image analysis, we found that the 6-phosphogluconate dehydratase polypeptide (spot N. 1 in Fig. 2) was present in both strains, and that its expression level in MV474 and in UW136 was not significantly different (Table1). Further analyses of the 2-DE protein profiles were focussed to compare the expression of enzymes differently regulated in MV474 in sucrose growing conditions [13]. The enzyme of the PHB biosynthetic operon [30] $\beta$-ketothiolase displayed increased expression with statistic significance in MV474 (Fig. 2, Table 1), thus explaining the 8 fold higher production of PHB in the RhdA null mutant than in the wild-type strain. Significant different expression level of aconitate hydratase polypeptides (spots N. 2 and N.3 in Fig.2) between MV474 and UW136 strains (Table 1) were found. Aconitate hydratase 2 was present in higher amounts in UW136 than in MV474, whereas aconitate hydratase 1 was over-expressed in MV474. In E.coli both aconitate hydratase enzymes process the substrate citrate, and it was found that aconitate hydratase 1 (the product of the $a c n A$ gene) was induced by oxidative stress [31]. Evidence that RhdA lack altered protection from oxidative events, thus giving rise to the loss of the functionality of enzymes containing labile Fe-S clusters [15], was provided by enzymatic analyses (Table 2). 6-phosphogluconate dehydratase activity in extracts from MV474 was about $60 \%$ of that found in UW136, although the polypeptide expression in both A.vinelandii strains did not show statistic significant difference, and aconitate hydratase activity in MV474 was about $40 \%$ of that of UW136. Evident in vitro re-activation (about 1.5 fold differences from untreated samples) of both dehydratases was obtained in extracts from MV474 (Table 2) after treatment with ferrous iron and dithiothreitol (DTT). Re-activation of Fe-S enzymes by treatment with ferrous iron and DTT is considered an indication that damage to the clusters stems from interaction with reactive oxygen species that induces the loss of iron [ 15 and references therein]. Moreover, a likely unbalance of oxidative events in the RhdA null mutant was suggested by the finding that the activity of the hydrogen peroxide scavenger catalase [32-34] was higher in MV474 than in UW136 (i.e. $30 \pm 2$ $\mathrm{U} / \mathrm{mg}$ and $50 \pm 2 \mathrm{U} / \mathrm{mg}$ in UW136 and MV474, respectively).

\section{Defensive action of the rhdA gene product (RhdA) against superoxide stress}

To evidence the involvement of RhdA in triggering protection processes to oxidative events, we analyzed the response of A.vinelandii MV474 and UW136 strains to induced oxidative stress. The resistance of A.vinelandii to the exposure to the oxidative agent phenazine methosulfate (PMS) was severely affected by the absence of RhdA (Fig. 3, Panel A). With regard to untreated control cultures, the growth of the rhdA mutant was less than $40 \%$, while the wild-type strain was not significantly affected by PMS treatment. Upon exposure to PMS, the decrease in aconitate hydratase activity, with regard to that measured in untreated extracts, was more pronounced in the rhdA mutant strain (5-fold) than in the wild-type (1.6-fold). As for 6-phosphogluconate dehydratase activity, $60 \%$ of that of untreated extracts was found in the wild-type strain, and $45 \%$ in the rhdA mutant.

To investigate whether treatment of A.vinelandii with the superoxide generator PMS could prime different defensive processes in the wild type and in the rhdA mutant strains, the 2-DE protein profiles of both strains were compared under conditions of exposure to PMS. Accurate matching of these protein profiles was performed with the purpose to detect protein spots underlying the different responses of MV474 to PMS treatment with regard to UW136. In PMS-treated MV474 a protein spot $\left(\mathrm{M}_{\mathrm{r}} \approx 20 \mathrm{kDa}, \mathrm{pI} \approx 5.2\right)$ that had never been detectable in untreated cells or in PMS- 
treated wild-type strain was revealed (Fig.3, Panel B). The MALDI-TOF MS analysis allowed its identification as Q4IS62_AZOVI, which is defined alkyl hydroperoxide reductase (AhpC), a member of the OxyR regulon [32-35]. Regulated adaptive responses of microorganisms to oxidative stress have been extensively studied using Escherichia coli as model organism [32, 36, 37], and it is generally recognized that catalase and alkyl hydroperoxide reductase activities are critical to oxidative stress survival.

Even though AphC was overexpressed in the rhdA null mutant as a likely defense mechanism, it did not endow A.vinelandii MV474 to show resistance to the exposure to PMS comparable with that of the wild-type strain (Fig.3, Panel A). This evidence indicated a role of the rhdA gene product in defending A.vinelandii against oxidative stress, and prompted us to explore whether RhdA protein underwent structural modifications involving sulphur redox chemistry [37-39]. Formation of RhdA dimer form was evidenced by RhdA immunodetection in UW136 cell extracts exposed to the PMS stressor (Fig.4). Considering that the RhdA Cys 230 catalytic thiol, the only one present in the protein $[12,40]$, is mandatory for sulfane sulphur transfer from thiosulfate to cyanide with concurrent formation of thiocyanate (TST activity) [1], thiocyanate production [23] represents a probe of $\mathrm{Cys}_{230}$ thiol availability. When the wild-type strain UW136 was exposed to PMS, the production of thiocyanate in extracts was $19 \%$ of that measured in untreated extracts. Restoration of thiocyanate production up to $98 \%$ of that of untreated cells was obtained by incubating the extracts from UW136 PMS-treated cells in the presence of the thioredoxin/thioredoxin reductase system. These results indicated that reversible modifications of RhdA Cys 230 thiol occurred in A.vinelandii. under oxidative conditions.

For the aim of investigating how RhdA itself could behave as a redox switch, we undertook an in vitro study to prove RhdA molecular modifications. Incubation of purified RhdA overexpressed in E.coli. [24] with PMS resulted in a time-dependent loss of its ability to produce thiocyanate (Fig.5A).

The effects of exposure to PMS on RhdA were concurrently analysed by non-reducing SDS-PAGE and MALDI-TOF MS . Non-reducing SDS-PAGE (Fig.5B), followed by accurate densitometric analysis of the resulting protein pattern (Fig. 5C and D, grey bars), revealed that exposure to PMS for up to 20 minutes increased the dimer to monomer ratio of RhdA with regard to the ratio in untreated samples. As shown in Fig. 5B and 5C, the presence of the RhdA dimeric form decreased when the PMS treatment was prolonged, thus indicating that RhdA inactivation during PMS treatment (Fig.5A) could not only be ascribed to the dimer formation. Further details on RhdA modifications that affect $\mathrm{Cys}_{230}$ thiol availability, were provided by MALDI-TOF MS. As shown in Fig. 5C and D(black bars), MALDI-TOF MS analysis of the dimer to monomer ratios of RhdA during PMS treatment confirmed that formation of RhdA dimer was inhibited by prolonged exposure to PMS. A molecular mass of $31024.5 \mathrm{~m} / \mathrm{z}$, corresponding to the protein containing unmodified Cys $_{230}$ (calculated molecular mass 31027.9) was measured by MALDI-TOF MS analyses of the untreated RhdA (Fig.6 A). When treated with PMS, a second peak with a molecular mass of $31056.7 \mathrm{~m} / \mathrm{z}$ was detected (Fig. $6 \mathrm{~B}$ ), suggesting the formation of a sulfinic acid $\left(\mathrm{Cys}_{230^{-}}\right.$ $\mathrm{SOOH})(+32 \mathrm{Da})$ [38]. When the experiments were repeated in the presence of equimolar ratio RhdA/PMS, MALDI-TOF MS analysis of the sample after a 60 minute exposure to PMS led to the detection of the peak corresponding to the unmodified protein, and a second peak with an increase in molecular mass of $16 \mathrm{Da}$ (data not shown) suggesting the presence of a sulfenic acid $\left(\mathrm{Cys}_{230^{-}}\right.$ $\mathrm{SOH})$. This latter peak disappeared after treatment with $\beta$-mercaptoethanol as reductant, and TST activity of the PMS-treated RhdA was recovered up to $60 \%$ of that of untreated sample by incubation in the presence of the thioredoxin/thioredoxin reductase system.

\section{DISCUSSION}

Among the 10 ORFs of A.vinelandii coding for rhodanese-domain proteins displaying different architecture and active-site motif (Accession number PF00581, Azotobacter vinelandii AvOP), the rhdA gene [11] codes for a tandem domain rhodanese (RhdA) with an active-site loop [12] which ensues a strong positive electrostatic field around the catalytic residue Cys230. Preliminary 
phenotypic characterization of the A.vinelandii strain disrupted in the rhdA gene [13] suggested that RhdA could exert some protection that allowed functioning in the cell enzymes containing Fe-S clusters prone to oxidation [15]. Consistently with this hypothesis, in the present study, we found that the phenotypic features due to the absence of RhdA were elicited using growth condition that strictly requires enzymes containing labile $\mathrm{Fe}-\mathrm{S}$ cluster as catalysts. In the presence of gluconate as carbon source, which implies the functioning of 4Fe-4S 6-phosphogluconate dehydratase [16-17], A.vinelandii growth was impaired only in the RhdA null mutant.

In this growth condition we found that in the RhdA null mutant aconitate hydratase 1 , which in E.coli is induced during oxidative stress [31] was overexpressed, and that the activity of the hydrogen peroxide scavenger catalase was enhanced. The presence in A.vinelandii of catalase enzymes inducible by reactive oxygen intermediates produced during respiration [41] was recently reported. As already found in sucrose-cultured rhdA null mutant [13], PHB accumulation, generally considered a "cell survival mechanism" [28-29], was increased in the RhdA mutant strain. The overall picture confirmed that deletion of the rhdA gene makes A.vinelandii more prone to stress, and the increased vulnerability of dehydratase Fe-S clusters in the RhdA mutant was further evidence proving that in the absence of RhdA protection from oxidative events was impaired. There is general consensus that oxidants convert the dehydratase $[4 \mathrm{Fe}-4 \mathrm{~S}]^{2+}$ form to an unstable $[4 \mathrm{Fe}-$ $4 \mathrm{~S}]^{3+}$ state, which releases the catalytic iron [15,42], an event that eventually induces the inactivation of the enzymes. Reactivation in vitro of the damaged enzymes by treatment with iron and dithiothreitol proves that inactivation involves the damage to the cluster [42]. The results of Table 2, combined with the analyses of polypeptide expression, indicated that the low catalytic efficiency of dehydratases in the RhdA null mutant was due to oxidative damage of the Fe-S cluster. To overcome oxidative damage due to the oxidizing potential of $\mathrm{O}_{2}$, eukaryotic and prokaryotic organisms have evolved strategies to remoye reactive oxygen species and repair damage [36-37]. The aerobe A.vinelandii was the focus of studies devoted to investigate the mechanisms of protection of nitrogenase complex from oxygen inactivation [43], but knowledge of physiological responses to the generation of oxidative species in non-diazotrophic conditions (examined in our studies) is lacking. When oxidative stress was provoked by the external addition of chemical oxidants (the superoxide generator PMS), we found that sensitivity of A.vinelandii was particularly pronounced only in the rhdA mutant strain. Overexpression of AhpC as an adaptive response to oxidative stress [32-37] did not endow the rhdA mutant to show PMS resistance comparable with that of A.vinelandii wild-type. In E. coli and in other bacteria, AhpC is a member of the OxyR regulon which upregulates peroxide defenses [34, 36]. In E.coli, the model organism of studies on adaptive responses OxyR-mediated, it was found that OxyR can respond to disulphide stress resulting from defects in the systems that maintain an intracellular reducing environment [44], and that the OxyR-regulated $a h p C$ transcript was induced by PMS [45]. Although OxyR-regulated responses in A.vinelandii are unknown, the presence in A.vinelandii chromosome of a gene (Avin48440, http://agro.vbi.vt.edu) coding for a protein homologous to OxyR could be taken as an indication that similar adaptive mechanisms exist in A.vinelandii. The picture that has emerged from the present study, which aimed to define physiological functions of the rhodanese-like RhdA, indicated that this protein might function as an antioxidant that helps A.vinelandii in "scavenging" oxidative species. Elimination of oxidative species does imply that RhdA can function as redox switch via thiol modifications, an ability that might be inferred by the structural peculiarity of the environment of its catalytic cysteine residue [12] that can promote ionization, even at neutral $\mathrm{pH}$, to the thiolate anion (Cys- $\left.\mathrm{S}^{-}\right)$. It is generally recognized [37-39] that thiolate anions are easily oxidized to the unstable sulfenic acid (Cys-SOH) which may react with accessible thiol to form disulfide (S-S) bond. The decreased availability of the RhdA Cys 230 -thiol in extracts from PMStreated A.vinelandii UW136, proved by RhdA activity tests, and the reversibility of the PMS effects in the presence of the thioredoxin-thioredoxin reductase reducing system, provided evidence that RhdA Cys 230 -thiol modifications in vivo occurred. Molecular details of RhdA Cys 230 thiol modifications (the only one present in the molecule) were explored by using an artificial situation. 
Formation of the RhdA dimeric form upon being exposed for a short period to PMS, and further oxidation producing the stable sulfinic acid species [38-39] was demonstrated by combining activity tests, electrophoretic and MALDI-TOF MS analyses. Also in the artificial situation of these in vitro studies, in the presence of the thioredoxin-thioredoxin reductase reducing system, RhdA Cys 230 thiol modifications were reduced back to the active thiol form mandatory for thiocyanate production. Although to study oxidative modifications of RhdA we used an in vitro approach, the RhdA functionality as cellular switch is supported by the in vivo evidence that in the absence of RhdA A.vinelandii needed to activate defensive activities generally recognized as adaptive response to cellular oxidative unbalance [36-37].

Acknowledgements: This work was carried out with the support of grants (awarded to S.P.) from Unimi FIRST 2006, 2007. We wish to thank Prof. Pasquale Ferranti for his invaluable advice on the identification of protein spots, and Dr. Simona Nonnis for the skilful assistance she provided in performing MALDI-TOF MS analyses

\section{REFERENCE}

[1] Westley, J., Adler, H., Westley, I., and Nishida, C. (1983) The sulfurtransferases. Fundam. Appl, Toxicol. 3, 377-382.

[2] Bordo, D., and Bork, P. (2002) The rhodanese/Cdc25 phosphatase superfamily. EMBO Rep. 3, 741-746

[3] Nandi, L.D. and Westley, J. (1998). Reduced thioredoxin as a sulfur-acceptor substrate for rhodanese. Int. J. Biochem. Cell Biol. 30, 973-977.

[4] Ray, W.K., Zeng, G., Potters, M.B., Mansuri, A.M. and Larson, T.J. (2000). Characterization of a 12-Kilodalton rhodanese encoded by glpE of Escherichia coli and its interaction with thioredoxin. J. Bacteriol. 182, 2277-2284.

[5] Williams, R.A.M., Kelly, S.M., Mottram, J.C. and Coombs G.H. (2003). 3-mercaptopyruvate sulfurtransferase of Leishmania contains an unusual C-terminal extension and is involved in thioredoxin and antioxidant metabolism. J. Biol. Chem. 278, 1480-1486.

[6] Nagahara, N., Katayama, A. (2005) Post-translational regulation of mercaptopyruvate sulfurtransferase via a low redox potential cysteine-sulfenate in the maintenance of redox homeostasis" J. Biol. Chem. 280, 34569-34576.

[7] Nagahara, N. Yoshii, T., Abe, Y, Matsumura, T. (2007) Thioredoxin-dependent enzymatic activation of mercaptopyruvate sulfurtransferase: an intersubunit disulfide bond serves as redox switch for activation. J. Biol. Chem. 282, 1561-1569

[8] Santos P. M., Benndorf D. and Sá-Correla (2004) Insights into Pseudomonas putida KT2440 response to phenol-induced stress by quantitative proteomics. Proteomics 4:2640-2652.

[9] - Krivobok S., Kuony S., Meyer C., Louwagie M., Willison J.C. and Juoanneau Y. (2003) Identification of pyrene-induced proteins in Mycobacterium sp. strain 6PY1:evidence for two ringhydroxylating dioxygenases. J. Bacteriol. 185:3828-3841.

[10] - Cavalca, L., Guerrieri, N., Colombo, M., Pagani, S., Andreoni, V. (2007) Enzymatic and genetic profiles in environmental strains grown on polycyclic aromatic hydrocarbons Antonie van Leeuwenhoek 91, 315-325

[11] Colnaghi, R., Pagani, S., Kennedy, C., Drummond, M. (1996). Cloning, sequence analysis and overexpression of the rhodanese gene of Azotobacter vinelandii. Eur. J. Biochem. 236, 240-248

[12] Bordo, D., Deriu, D., Colnaghi, R., Carpen, A., Pagani S., Bolognesi M. (2000). The crystal structure of a sulfurtransferase from Azotobacter vinelandii highlights the evolutionary relationship between rhodanese and phosphatase enzymes family. J. Mol. Biol. 298, 691-704.

[13] Cereda, A., Carpen, A., Picariello, G., Iriti, M ., Faoro, F., Ferranti, P., Pagani, S. Effects of the deficiency of the rhodanese-like protein RhdA in Azotobacter vinelandii.(2007) FEBS Letters $581,1625-1630$

[14] Keyer, K., Imlay, JA. (1997) Inactivation of dehydratase 4Fe-4S clusters and disruption of iron homeostasis upon cell exposure to peroxynitrite. J. Biol. Chem. 272, 26652-27659 
[15] Imlay, JA. (2006) Iron-sulphur clusters and the problem with oxygen. Mol. Microbiol. 59, 1073-1082

[16] Peekhaus, N. and Conway, T. (1998) What's for Dinner?: Entner-Doudoroff metabolism in Escherichia coli J. Bacteriol. 180, 3485-3502

[17] Gardner P.R. and Fridovich, I. (1991) Superoxide sensitivity of the Escherichia coli 6phosphogluconate dehydratase. J.Biol.Chem. 266, 1478-1483

[18] Blum, H., Beler, H., Gross, HJ.(1987) Improved silver staining of plant proteins, RNA and DNA in polyacrylamide gels. Electrophoresis, 8, 93-99

[19] Shevchenko, A., Wolm, M., Vorm, O., Mann, M. (1996) Mass spectrometric sequencing of proteins silver-stained polyacrylamide gels. Anal. Chem. 68, 850-858.

[20] Varghese, S.,Tang, Y., Imlay, J.A.,(2003) Contrasting sensitivities of Escherichia coli Aconitases A and B to oxidation and iron depletion. J. Bacteriol. 185, 221-230

[21] Outten, F.W., Djaman, O., Stortz, G.,(2004) A suf operon requirement for Fe-S cluster assembly during iron starvation in Escherichia coli,molecular microbiology, 52, 861-872

[22] Beers,R.F. Sizer, I.W.1952 A spectrophotometric method for measuring the breakdown of hydrogen peroxide by catalase. J. Biol. Chem.195, 133-140.

[23] Sorbo, B.H. (1953) Crystalline rhodanese. Purification and physiochemical examination. Acta Chem. Scand. 7 pp. 1129-1136

[24] Forlani, F., Carpen, A., and Pagani, S.(2003) Evidence that elongation of the catalytic loop of the Azotobacter vinelandii rhodanese changed selectivity from sulfur- to phosphate-containing substrates. Protein Eng. 16, 515-519

[25] Laemmli, UK. (1970) Cleavage of structural proteins during the assembly of the head of bacteriophage T4. Nature, 227, 680-685

[26] [Bradford, M.M (1976). A rapid and sensitive method for the quantitation of microgram quantities of protein utilizing the principle of protein-dye binding. Anal. Biochem. 72, $248-254$

[27] Law J. H, Slepecky R.A. (1961) Assay of poly- $\beta$-hydroxybutyric acid. J. Bacteriol. 82, 33-36

[28] Anderson, AJ., and Dawes, EA. (1990) Occurrence, metabolism, metabolic role, and industrial uses of bacterial polyhydroxyalkanoates. Microbiol. Rev. 54, 450-472

[29] Ayub, ND., Pettinari, MJ., Ruiz, JA., Lopez, NI. A polyhydroxybutyrate-producing Pseudomonas sp. Isolated from antarctic environments with high stress resistance (2004) Current Microbiology 49, 170-174

[30] Peralta-Gil, M., Segura, D., Guzman, J., Servin-Gonzalez, L., Espin, G. (2002) Expression of the Azotobacter vinelandii poly- $\beta$-hydroxybutyrate biosynthetic phbBAC operon is driven by two overlapping promoters and is dependent on the transcriptional activator PhbR. J. Bacteriol. 184, 5672-5677

[31] Cunningham, L.,Gruer, MJ, \& Guest, JR. 1997 Transcriptional regulation of the aconitase genes (acnA and acnB) of Escherichia coli Microbiology 143, 3795-3805

[32] Zheng,M., Wamg, X., Templeton,LJ., Smulski,DR., LaRossa,RA., Storz, G. (2001) DNA microarray-mediated transcriptional profiling of the Escherichia coli response to hydrogen peroxide. J. Bacteriol. 183, 4562-4570

[33] Ochsner, UA., Maj, M., Nicholls, P. and Loewen, P. (2000) Role of the Pseudomonas aeruginosa oxyR-recG operon in oxidative stress defense and DNA repair: OxyR-dependent regulation of the katB-ankB,ahpb and $a h p C-a h p F$. J. Bacteriol. 182, 4533-4544

[34] Hishinuma,S., Yuki, M., Fujimura, M., and Fukumori, F. (2006) OxyR regulated the expression of two major catalases, KatA and KatB, along with peroxiredoxin, AhpC in Pseudomonas putida. Environmental Microbiology 8, 2115-2124

[35] Costa Seaver, L. and Imlay, JA. (2001) Alkyl hydroperoxide reductase is the primary scavenger of endogenous peroxide in Escherichia coli. J. Bacteriol. 183, 7173-7181

[36] Pomposiello, PJ., and Demple, B. (2001) redox-operated genetic switches:the SoxR and OxyR transcription factors. TRENDS Biotechnol. 19, 109-114

[37] Kiley, PJ., Storz, G. (2004) Exploiting thiol modifications Plos Biol. 2(11), 1714-1717 
[38] Jacob, C., Knight, I., and Winyard, PG. 2006 Aspects of the biological redox chemistry of cysteine: from simple redox responses to sophisticated signalling pathways. Biol.Chem. 387, 13851397

[39] Giles, GI. And Jacob, C. "Reactive sulphur species: an emerging concept in oxidative stress" (2002) Biol.Chem. 383, 375-388

[40] Bordo, D., Forlani, F., Spallarossa, A., Colnaghi, R., Carpen, A., Bolognesi, M., Pagani, S. (2001). A persulfurated cysteine promotes active-site reactivity in Azotobacter vinelandii rhodanese. Biol. Chem. 382, 1245-1252.

[41] Sandercock, JR. and Page, WJ. (2008) RpoS expression and the general stress response in Azotobacter vinelandii during Carbon and Nitrogen diauxic shifts. J. Bacteriol. 190, 946-953

[42] Flint, DH., Tuminello, JF., Emptage,MH. (1993) The inactivation of Fe-S cluster containing hydro-lyases by superoxide J.Biol.Chem. 268, 22369-22376

[43] Oelze, J. Respiratory protection of nitrogenase in Azotobacter species: is a widely held hypothesis unequivocally supported by experimental evidence? (2000) FEMS Microbiol. Rev. 24, 321-333

[44]_Aslund. F., Zheng, M, Beckwith, J. and Storz, G. (1999) Regulation of the OxyR transcription factor by hydrogen peroxide and the cellular thiol-disulfide status. Proc.Natl.Acad.USA 96, 61616165

[45] Lee JH., Yeo, WS., Roe, JH. (2004) Induction of the SufA operon encoding Fe-S assembly proteins by superoxide generators and hydrogen peroxide: involvement of OxyR, IHF and an unidentified oxidant-responsive factor. Mol. Microbiol. 51, 1745-1755 


\section{LEGENDS}

Fig.1 The lack of RhdA affects A.vinelandii growth on gluconate as carbon source. Growth of of A.vinelandii wild-type UW136 (solid circle) and rhdA mutant MV474 (open circle) in BGN medium was determined by measuring the OD at $600 \mathrm{~nm}$. Three independent experiments were carried out, one typical set is shown here.

Fig.2 Representative 2-DE gel images of A.vinelandii UW136 and MV474 strains. Whole cell extracts from A.vinelandii wild-type UW136 and rhdA mutant MV474 strains grown aerobically up to an $\mathrm{OD}_{600}=2.0$ in $\mathrm{BGN}$ medium, were separated by two-dimensional electrophoresis as described under Experimental Procedures. The silver-stained gels of UW136 and MV474 are shown, and the number represent the spots identified by MALDI-TOF MS listed in Table 1.

Fig. 3. Effects of the exposure to Phenazine Methosulfate on A.vinelandii wild-type and rhdA mutant strains.

A.vinelandii UW136 and MV474 strains were grown aerobically in BGN medium (supplemented with $0.2 \%$ gluconate) up to an $\mathrm{OD}_{600}=0.800$, then the cultures of either UW136 or MV474 strains were divided into two equal samples one of which was treated with phenazine methosulfate (PMS, final concentration $15 \mu \mathrm{M}$ ). The cultures were grown for $16 \mathrm{~h}$, subsequent to which growth was measured in terms of absorbance at $600 \mathrm{~nm}$, and two-dimensional PAGE was performed as described in the legend of Fig.2. Three independent experiments were carried out. Panel A shows the $\mathrm{OD}_{600}$ recorded after $16 \mathrm{~h}$ exposure to PMS and the value recorded for PMS-untreated cultures. Panel B represents the zoom-in on the region of the 2-DE pattern showing AhpC (Q4IS62) protein spot (indicated by the arrow). From left to right: untreated UW136, untreated MV474, PMS-treated UW136 and PMS-treated MV474.

\section{Fig.4 SDS-PAGE immunoblot}

Proteins from cell extracts $(40 \mu \mathrm{g}$ protein) either from UW136 after $16 \mathrm{~h}$ exposure to the PMS stressor or from untreated UW 136 were resolved by non-reducing SDS-PAGE and subjected to Western blot analysis with anti-RhdA antibodies [13]. The stars indicate the dimeric and monomeric forms of RhdA, respectively.

\section{Fig. 5 Oxidative events on RhdA.}

Purified RhdA overexpressed in E.coli. $(100 \mu \mathrm{M})$ in $50 \mathrm{mM}$ Tris- $\mathrm{HCl} \mathrm{pH} 8,100 \mathrm{mM} \mathrm{NaCl}$ was incubated aerobically at room temperature.with PMS (final concentration $1 \mathrm{mM}$ ). At fixed times of PMS exposure, samples were withdrawn and analyzed in terms of ability to produce thiocyanate (TST activity), electrophoretic pattern, and Mass Spectrometric analyses. Panel A shows timedependent inactivation of RhdA by PMS, indicated as activity percentages in relation to_the untreated RhdA. (time 0).

Panel B: nonreducing SDS-PAGE of the samples at the indicated times of exposure to PMS. The stars indicate the dimeric and monomeric forms of RhdA, respectively.

Panel $C$ and $D$ show the dimer to monomer ratios of RhdA before (time 0 ), and in the course of PMS treatment determined either by densitometric analyses of the electrophoretic patterns (grey bars) or MALDI-TOF MS analyses (black bars). In panel D values are normalized with reference to those before treatment ( 0 min.).

Fig. 6 MALDI-TOF MS analysis of RhdA before and after oxidation by PMS . Panel $A$ and $B$ show the mass spectra of RhdA before and after 20 min treatment with PMS (molar ratio RhdA/PMS 1/10), respectively. Spectra were recorded in positive linear mode. 


\section{Table 1 : Identified proteins by MALDI-TOF MS analysis}

The relative abundance $(\% \mathrm{~V})$ of 6-phosphogluconate dehydratase (N. 1, Q4ITN0), Aconitate hydratase 1 (N.2, Q4IW32), Aconitate hydratase 2 (N.3, Q4J5V0), acetoacetyl-CoA reductase (N. 4, Q93QF0) and $\beta$-ketothiolase (N.5, Q9KH97) was deteinined in 5 experimental repeats, and used to calculate the protein ratio MV474/UW136.

\section{Spot number Protein name}

1 6-phosphogluconate dehydratase

2

3

4

5

a: Swiss-Prot/TrEMBL database. n.s.d.: not significantly different

Aconitate hydratase 1

Aconitate hydratase 2

Acetoacetyl-CoA reductase

$\beta$-ketothiolase

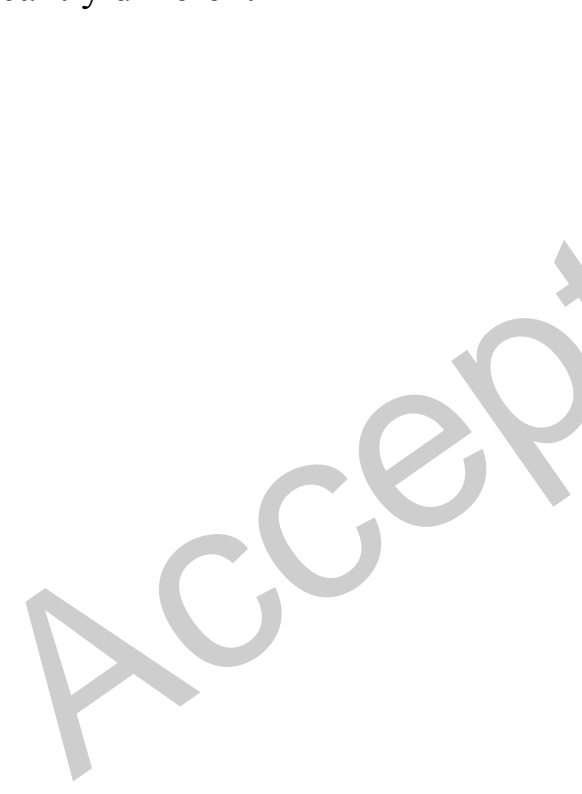

Accession number ${ }_{a}$ Sequence coverage (\%)

$$
\text { 응 }
$$
Mr?pI

\section{(1)} $\underset{\sim}{\mathrm{N}}$

Q4ITN0

Q4IW32

Q4J5V0

Q93QF0

Q9KH97 $65348 \mathrm{kDa} / 6.0$ $97214 \mathrm{kDa} / 5.3$ $93187 \mathrm{kDa} / 5.5$ $26226 \mathrm{kDa} / 6.2$ $40875 \mathrm{kDa} / 6.7$

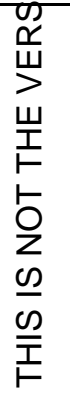
Protein ratio(MV474/UW136)

n.s.d.

$1.37 \pm 0.02$

$-0.69 \pm 0.02$

n.s.d.

$1.23 \pm 0.07$ 


\section{Table 2 : Activity of dehydratase enzymes in A.vinelandii wild-type and rhdA mutant strains.}

A.vinelandii UW136 and MV474 strains were grown aerobically in BGN medium up to an $\mathrm{OD}_{600}=$ 2.0 .

6-phosphogluconate dehydratase and aconitate hydratase activities were determined in samples (150-300 $\mu \mathrm{g}$ of proteins) of cell-free extracts anaerobically prepared. Aconitate hydratase and 6phosphogluconate dehydratase activities were referred as $\mu \mathrm{mol}$ cis-aconitate formed $\mathrm{min}^{-1} \mathrm{mg}$ protein ${ }^{-1}$ and $\mu \mathrm{mol}$ pyruvate formed $\mathrm{min}^{-1} \mathrm{mg}_{\text {protein }}{ }^{-1}$, respectively. For reactivation experiments, before the activity tests, the cell-free extracts were anaerobically incubated $(10 \mathrm{~min})$ at room temperature in the presence of $\mathrm{FeSO}_{4}(1.0 \mathrm{mM})$ and DTT $(5.0 \mathrm{mM})$. The means of 6 independent growth experiments are presented.

\begin{tabular}{lcc}
\hline & A.vinelandii UW136 & A.vinelandii MV474 \\
\hline Basal activity of: & & \\
6-phosphogluconate dehydratase & $0.620 \pm 0.012$ & $0.39 \pm 0.007$ \\
Aconitate hydratase & $2.05 \pm 0.07$ & $0.84 \pm 0.05$ \\
& & \\
Activity after treatment with $\mathrm{FeSO}_{4}$ and $\mathrm{DTT}$ & $0.560 \pm 0.007$ \\
6-phosphogluconate dehydratase & $0.700 \pm 0.006$ & $1.27 \pm 0.21$ \\
Aconitate hydratase & $2.31 \pm 0.20$ &
\end{tabular}


B Biochemical Journal Immediate Publication. Published on 17 Oct 2008 as manuscript BJ20081218

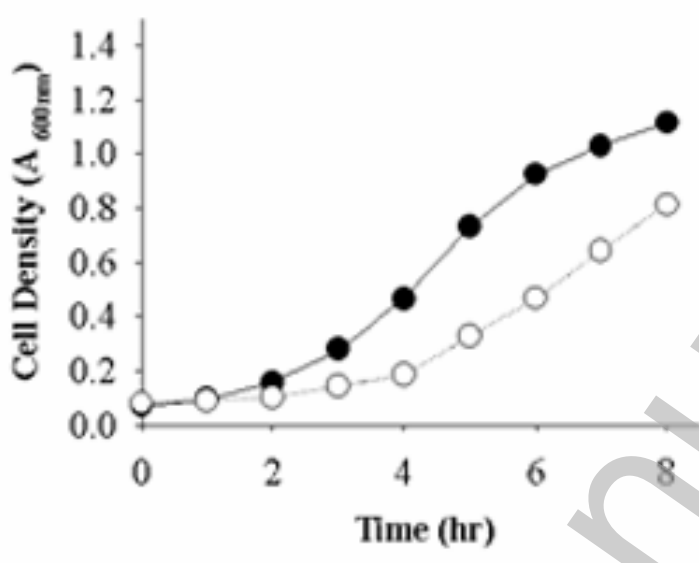

Fig.1 


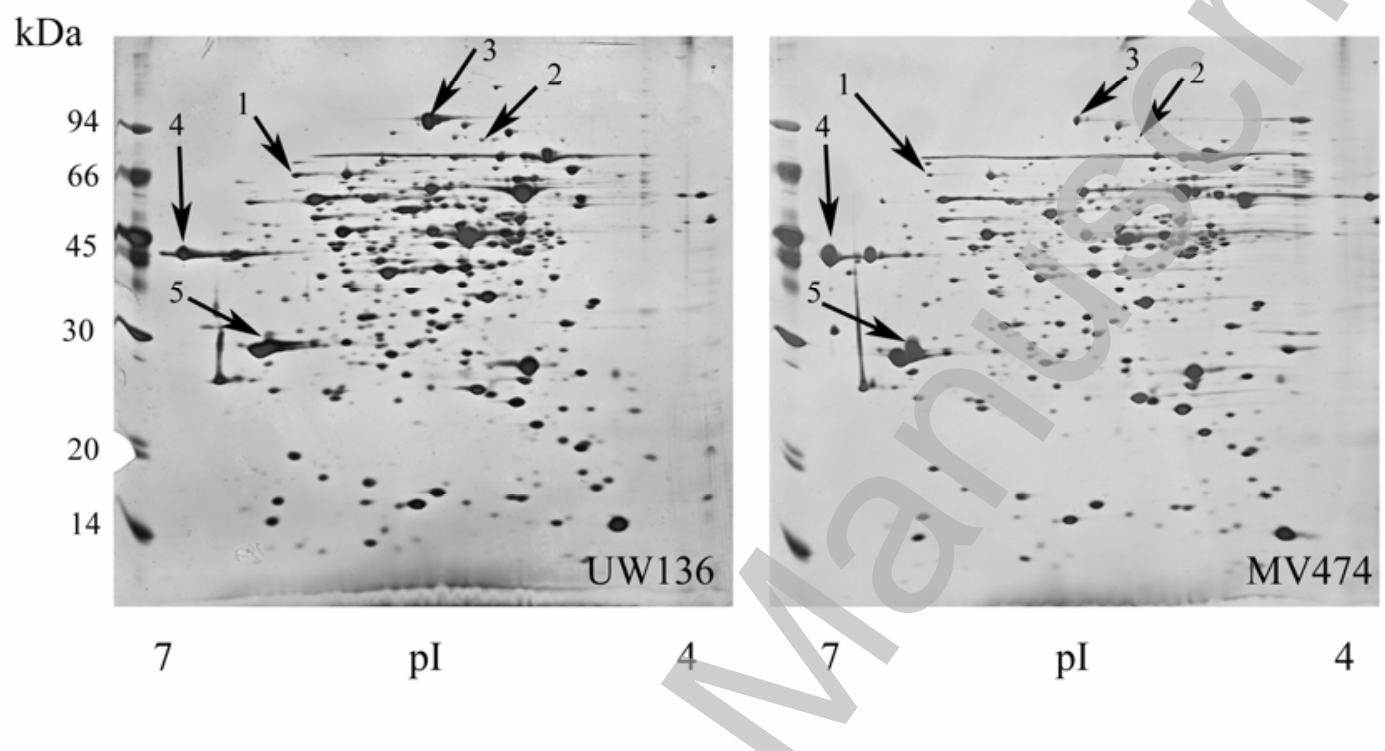

Fig. 2 
B Biochemical Journal Immediate Publication. Published on 17 Oct 2008 as manuscript BJ20081218
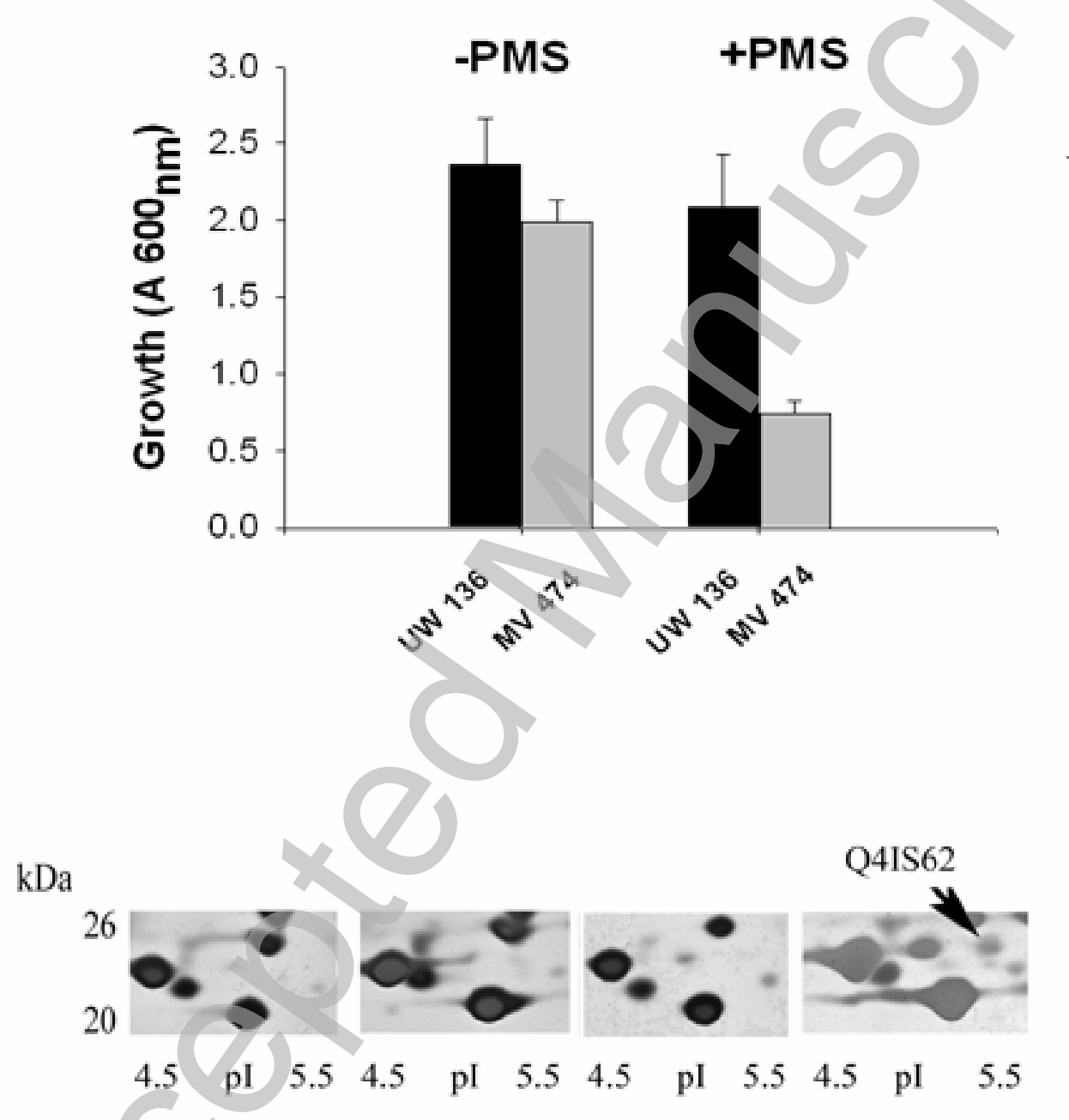

A

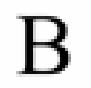

\section{Fig.3}


A
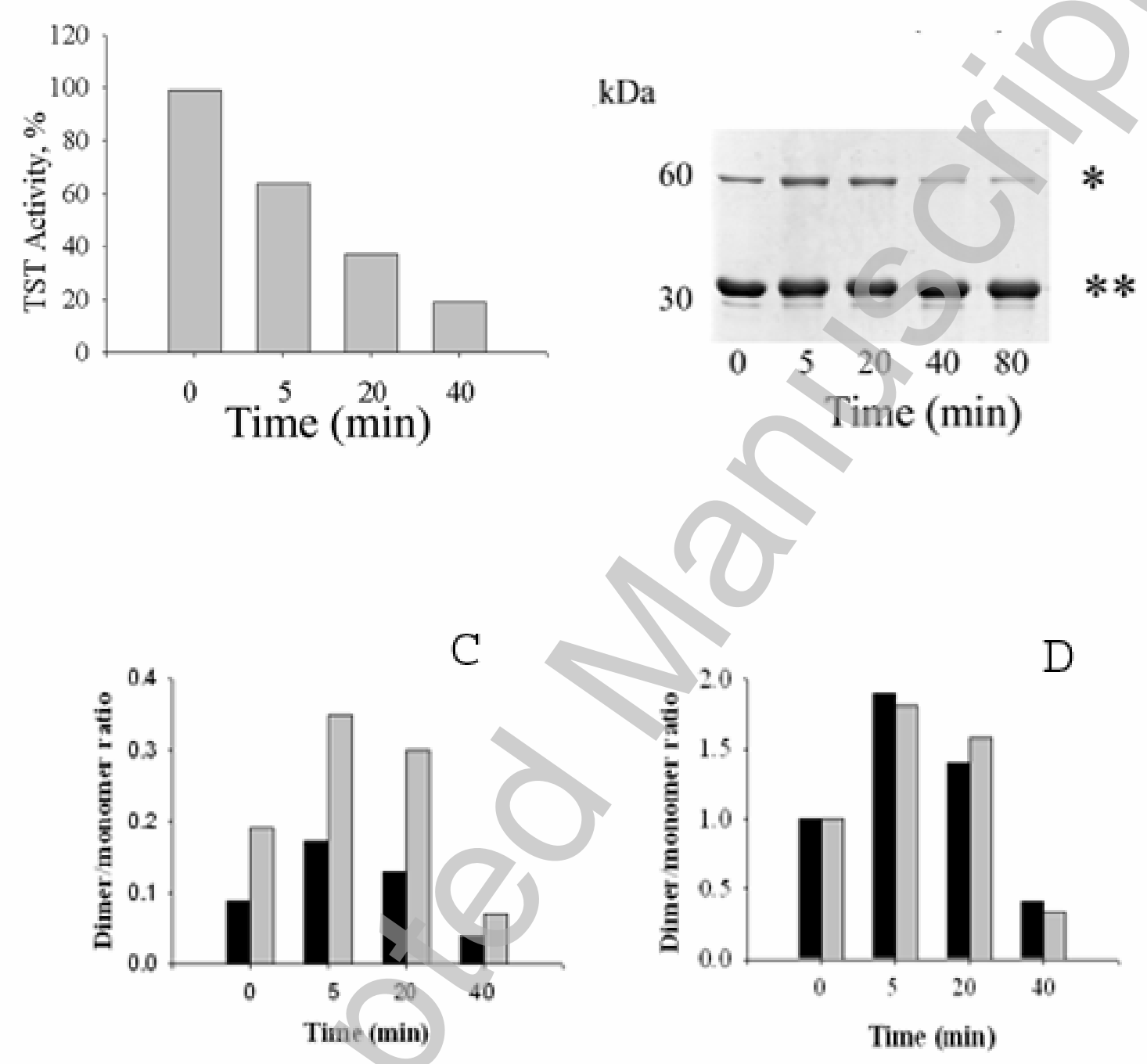

\section{Fig.5}




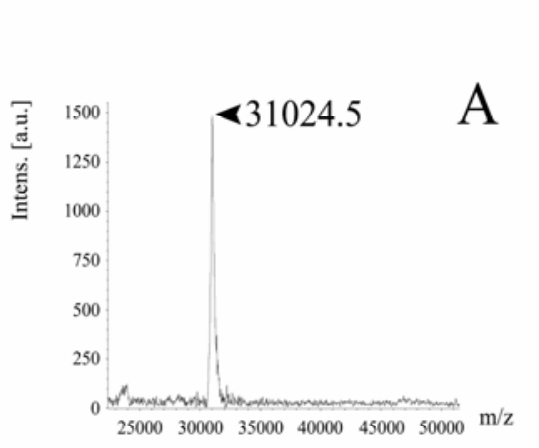

